\title{
Seasonal, Diurnal and Wind-Direction-Dependent Variations of the Aerodynamic Roughness Length in Two Typical Forest Ecosystems of China
}

\author{
Yanlian Zhou ${ }^{1}$, Xiaomin Sun ${ }^{2, *}$, Weimin Ju ${ }^{3}$, Xuefa Wen ${ }^{2}$, and Dexin Guan ${ }^{4}$ \\ ${ }^{1}$ School of Geographic and Oceanographic Sciences, Nanjing University, Nanjing, China \\ ${ }^{2}$ Key Laboratory of Ecosystem Network Observation and Modeling, Institute of Geographic Sciences \\ and Natural Resources Research, Chinese Academy of Science, Beijing, China \\ ${ }^{3}$ International Institute for Earth System Science, Nanjing University, Nanjing, China \\ ${ }^{4}$ Institute of Applied Ecology, Chinese Academy of Sciences, Shenyang, China
}

Received 27 May 2011, accepted 6 October 2011

\begin{abstract}
Aerodynamic roughness length $\left(z_{o m}\right)$ is an important parameter for reliably simulating surface fluxes. The parameter varies with wind speed, atmospheric stratification, terrain and other factors; however, variations of this parameter are not properly considered in most models, which may result in uncertainties in simulating surface latent heat and sensible heat flux. There have been few studies of the diurnal and wind-direction dependent variations in $z_{\text {om }}$. This study analyzes the seasonal, diurnal and wind-direction-dependent variations in $z_{o m}$ calculated from the profile of meteorological data for two forest systems of China, and explores the mechanism underlying these variations.

Annually averaged and monthly averaged diurnal variations in $z_{o m}$ are obvious and similar at a Changbai Mountain (CBS) site located in northeast China and a Qianyanzhou (QYZ) site located in southeast China. $z_{o m}$ is much higher at night than during the day. The diurnal variation in $z_{o m}$ is due to a change in atmospheric stratification. The seasonality of $z_{o m}$ differs at two sites. $z_{o m}$ has sizable seasonal variation and is lower in the leaf-off season than in the growing season at CBS. At QYZ, $z_{o m}$ does not have an obvious seasonal pattern. However, at QYZ, the short-term fluctuation is greater than that at CBS. The obvious seasonal variation in $z_{o m}$ at CBS is related to the great seasonal change in the leaf area index. The noticeable short-term winddirection-dependent variations in $z_{\text {om }}$ at $\mathrm{QYZ}$ are attributed to the heterogeneous terrain there.
\end{abstract}

Key words: Aerodynamic roughness, Seasonal variation, Diurnal variation, Wind-direction-dependent variation

Citation: Zhou, Y., X. Sun, W. Ju, X. Wen, and D. Guan, 2012: Seasonal, diurnal and wind-direction-dependent variations of the aerodynamic roughness length in two typical forest ecosystems of China. Terr. Atmos. Ocean. Sci., 23, 181-191, doi: 10.3319/TAO.2011.10.06.01(A)

\section{INTRODUCTION}

Mass and energy exchanges at the land surface-atmosphere interface are the most critical components of the climate system (Hurtalová and Matejka 1999), surface latent heat flux (LE) and sensible heat flux (SH) play an especially key role in determining weather and climate at various scales. Therefore, an accurate simulation of LE and SH is of importance to numerical models with regard to weather, climate, hydrology and ecology. Different methodologies are currently employed for calculating LE and SH such as algorithms based on remote sensing and numerical simulation models built on the basis of principles governing ener-

\footnotetext{
* Corresponding author

E-mail:sunxm@igsnrr.ac.cn
}

gy exchange and transfer in the soil-vegetation-atmosphere continuum.

Aerodynamic roughness length $z_{o m}$ is an important parameter for calculating LE and SH. Theoretically, $z_{o m}$ is the height above the surface at which the mean logarithmic wind profile reaches zero (Monteith 1973). Previously, land surface was generally treated as completely homogeneous. Therefore, $z_{o m}$ was considered as a parameter related only to rough elements in the fetch and was calculated by fitting the wind speeds at several different levels above the ground. Monteith (1973) summarized the relationship between $z_{\text {om }}$ and the height of rough elements and approximated the ratio of $z_{o m}$ to the averaged rough-element height $\left(z_{o m} / h\right)$ as 0.136 . Many empirical relations for calculating $z_{o m}$ have been developed recently. For vegetation with incomplete canopies, 
$z_{o m}$ is smaller and the $z_{\text {om }} / h$ relationship seems to vary more than for vegetation with closed canopies (Riou et al. 1987). Driese and Reiners (1997) reported averaged $z_{o m} / h$ values of $0.04,0.04$ and 0.13 for natural sagebrush, saltbush and greasewood, respectively. Van Dijk et al. (2004) found that $z_{o m} / h$ is 0.03 for a rain-fed cropping system with maize and cassava rotations. Some researchers have parameterized $z_{\text {om }}$ as a function of $h$, frontal area index or leaf area index (LAI) (Schaudt and Dickinson 2000; Nakai et al. 2008a). However, empirical estimates of $z_{o m}$ are still used in many models. For example, $z_{o m}$ is considered as $0.136 h$ in the Surface Energy Balance System (SEBS) model (Su et al. 2001, 2002). Langensiepen et al. (2009) calculated transpiration using the Penman-Monteith equation with $z_{o m}$ set to $0.13 \mathrm{~h}$. Sánchez et al. (2009) fixed $z_{\text {om }}$ as $0.1 h$ to calculate energy fluxes.

In those models, $z_{o m}$ was assumed to change with the averaged rough-element height. Instead, ground surfaces are rarely homogeneous and uniform. In the case of regularly undulating topography, drag is a function of the surface terrain height and increases with terrain slope. In this case, $z_{o m}$ is related not only to the height of rough elements, but also to the distribution, density and geometry of rough elements. This parameter also depends on the surface-air temperature difference and atmospheric conditions. Therefore, $z_{o m}$ is affected by the integrated effects of aerodynamic and thermodynamic factors and rough elements, which means that $z_{o m}$ is actually a parameter varying with wind speed, wind direction, terrain, atmospheric stratification, and LAI (Zhang et al. 2004; Patil 2006; Zhou et al. 2006).

There have been studies on the seasonal variations of $z_{o m}$, but few on the diurnal variations of $z_{o m}$. Usually, $z_{o m}$ is taken as an invariant parameter and the inherent temporal variability is ignored in many models calculating LE and SH. These models neglect concomitant effects on momentum transfer, and thus there are definite uncertainties in the simulated LE and SH (Borak et al. 2005). Through a sensitivity analysis, Kustas et al. (1989) concluded that the er- ror in a simulated SH would decrease by approximately an order of magnitude if $z_{o m}$ increased from 0.01 to $0.1 \mathrm{~m}$. Additionally, Pitman (1994) pointed out that an error of $30 \%$ in $z_{o m}$ corresponds to a $15 \%$ uncertainty in the calculation of surface fluxes. Teixeira et al. (2008) analyzed energy fluxes and vegetation-atmosphere parameters in irrigated and natural ecosystems of semi-arid Brazil, and pointed out that the variability of aerodynamic resistance could be mainly explained by the friction velocity $(u *)$, which in turn depends on $z_{o m}$. Ignorance of variations in $z_{o m}$ will inevitably result in the failure of models to capture the seasonal or diurnal patterns of carbon, energy and water fluxes. Therefore, variations in $z_{\text {om }}$ and corresponding effects on simulated fluxes need extra attention.

The primary objectives of this study are to (1) gain insight into the seasonal and diurnal variations of $z_{o m}$ in two typical forest ecosystems in China and (2) explore possible factors driving $z_{o m}$ variations in these two forest ecosystems.

\section{DATA AND METHODS USED}

\subsection{Sites Description}

Measurements taken from 1 January 2003 to 31 December 2004 at Qianyanzhou (QYZ) and Changbai Mountain (CBS) experimental stations were used in this study. The two stations belong to the ChinaFLUX network. QYZ $\left(26^{\circ} 44^{\prime} 52^{\prime \prime} \mathrm{N}, 115^{\circ} 03^{\prime} 47^{\prime \prime} \mathrm{E}\right)$ is located on a hilly field of southwestern Jiangxi Province, China. The elevation at the flux tower site is $102 \mathrm{~m}$ above sea level. The flux tower is located in a sloping field with an elevation of $2.8-13.5^{\circ}$. The topography surrounding the tower is heterogeneous and the relative elevation range is 20 to $50 \mathrm{~m}$ (Fig. 1), so in the footprint region, the topography is relative flat. The vegetation is a planted forest composed mainly of evergreen marsh pine, masson pine and fir. There are 1773 stems per hectare in forest. The maximum LAI is 3.6, with small annual and sea-
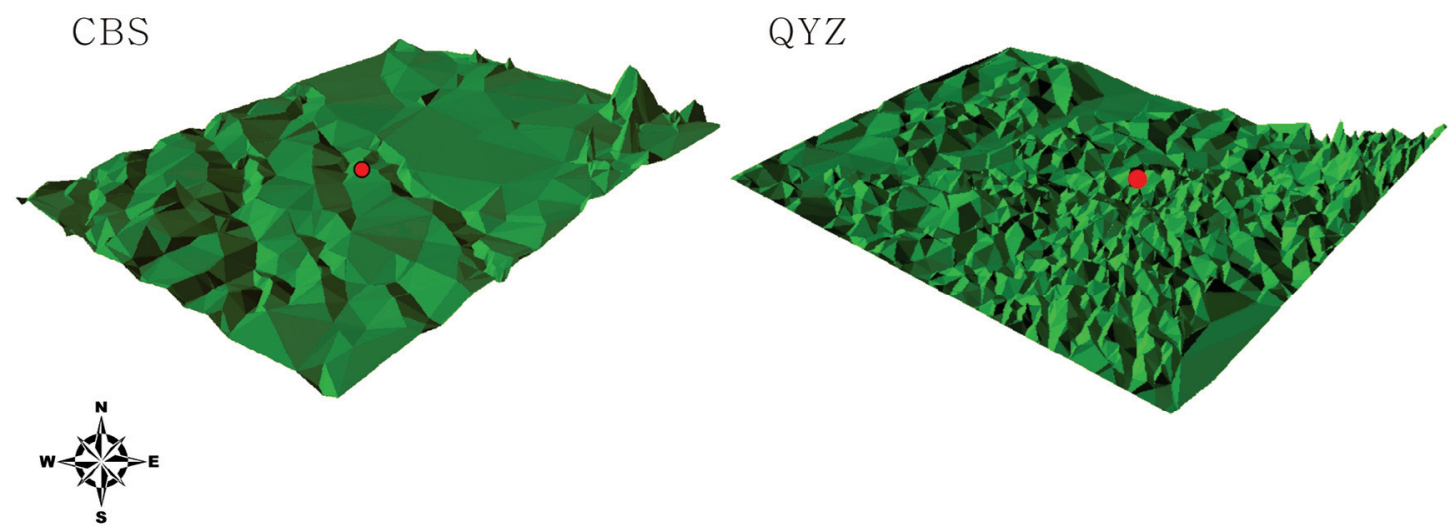

Fig. 1. The topographic maps of CBS (left, $125-130^{\circ} \mathrm{E}, 40-45^{\circ} \mathrm{N}$ ) and QYZ (right, $114-118^{\circ} \mathrm{E}, 24-28^{\circ} \mathrm{N}$ ). The pentagram represents the location of the observation tower. The two maps were made with ArcGIS software from DEM data provided by the Data-Sharing Network of Earth System Science of China. The spatial solution of the DEM data is $90 \mathrm{~m}$ by $90 \mathrm{~m}$. 
sonal variations (Liu et al. 2005, 2006). CBS $\left(41^{\circ} 24^{\prime} 09^{\prime \prime} \mathrm{N}\right.$, $\left.128^{\circ} 05^{\prime} 45^{\prime \prime} \mathrm{E}\right)$ is located in the southeast of Jilin Province, China. The elevation at the tower site is $761 \mathrm{~m}$. The tower is located in flat area, and the topography is predominately flat, with slopes of less than $4 \%$ (Fig. 1). The vegetation is a mature, natural, temperate, broad-leaved Korean pine forest of the Changbai Mountains, with the dominant species being Pinus koraiensis, Tilia Amurensis, Quercus Mongolia, Fraxinus mandshurica and Acer Mono. There are 560 stems per hectare with a canopy coverage of over $80 \%$ in a forest. And the mean canopy height is about $26 \mathrm{~m}$. The LAI varies from 2 in the winter to 6 in the summer (Guan et al. 2005; Zhang et al. 2006). Canopy height is important for calculating $z_{o m}$. Recently Nakai et al. (2008b and 2010) proposed new methods to determine the aerodynamic canopy height or cumulative basal area inflection $(\mathrm{CuBI})$ height, which are very useful for further micrometeorological studies. In this study, the canopy height was determined from the average measurements of an altimeter, which was commonly used by Chinaflux. The average canopy height in QYZ and CBS is 12 and $26 \mathrm{~m}$, respectively.

Because of the influence of the eastern Asian monsoon, the climate in Asia differs from that in Europe and that in North America, with there being apparent latitudinal gradients of temperature and precipitation along the NorthSouth Transect of Eastern China (NSTEC). Both CBS and QYZ are located in the NSTEC. They are typical ecosystems representing a temperate mixed forest and subtropical coniferous plantation, respectively. A deep understanding of the characteristics of $z_{o m}$ will be helpful for improving the simulations of carbon, water, and energy fluxes in forest ecosystems of China.

\subsection{Data Used}

At both QYZ and CBS, a seven-level routine meteorological profile system was mounted on the tower with an analyzer (Compbell Inc., USA). Within and above the forest air temperature and relative humidity (HMP45C, Vaisala Inc.), wind speed (A100R, Vector Inc.), wind direction (W200P, Vector Inc.), atmospheric pressure (CS105, Vaisala Inc.) and PAR (Li-Cor Inc., USA) were measured simultaneously. At QYZ, the measurements were taken at 1.6, 7.6, 11.6, 15.6, 23.6, 31.6, $39.6 \mathrm{~m}$ above the ground, respectively, while heights of measurements were taken at $2.0,8.0,22.0,26.0,32.0,49.8,61.8 \mathrm{~m}$ above the ground at CBS. Half-hourly measurements of meteorological variables at the uppermost four levels were used to calculate $z_{o m}$. If wind speed in the uppermost layer was lower than $1 \mathrm{~m} \mathrm{~s}^{-1}$, the data were excluded in further analysis. The LAI was derived from photosynthetically active radiation measured above and below the canopy (Baldocchi 1994; Soegaard and Thorgeirsson 1998). There were some data gaps because instruments were out of operation, and the gaps were inter- polated (Falge et al. 2001; Li et al. 2008). At both stations, all meteorological instruments were installed in appropriate directions to avoid the affect of the tower's presence. The measurements of wind speed and direction show that there were no obvious diurnal and seasonal tendencies in wind directions in 2003 and 2004 at both QYZ and CBS.

\section{3 $z_{\text {om }}$ Calculation Method}

There are four typical methods for calculating $z_{o m}$ using meteorological data recorded at several heights above the ground and/or data recorded by a three-dimensional sonic anemometer at one height (Berkowicz et al. 1982; Dolman 1986; Zhang and Chen 1997; Martano 2000; Gao et al. 2002; Takagi et al. 2003). The traditional least-squares method was employed here to calculate $z_{o m}$ from wind speed and temperature profiles since a previous study demonstrated that this method is the best for calculating $z_{o m}$ under all atmospheric stratifications at the two sites (Zhou et al. 2007).

\subsubsection{Least-Squares Method for Calculating $z_{o m}$ and $u *$}

Wind speed and temperatures measured at four heights can be expressed as

$$
\begin{aligned}
& u=\frac{u *}{k}\left[\ln \left(\frac{z-d}{z_{o m}}\right)-\psi_{m}\left(\frac{z-d}{L}\right)\right] \\
& \theta=\frac{\theta *}{k}\left[\ln \left(\frac{z-d}{z_{o h}}\right)-\psi_{h}\left(\frac{z-d}{L}\right)\right]+\theta_{0}
\end{aligned}
$$

where $u$ is the wind speed, $u *$ is the friction velocity, $k$ is the von Karman constant and equals $0.4, z$ is the height at which the wind speed and temperature are measured, $\theta$ is the potential air temperature of each layer, $\theta^{*}$ is friction temperature, $z_{\text {oh }}$ is the thermal roughness length, and $\theta_{0}$ is the potential temperature near the surface. $L$ is the Obukhov length, which is calculated as

$L=\frac{u *^{2} \theta}{\theta * k g}$

where $g$ is the acceleration due to gravity and equals 9.8. $\theta$ is calculated as

$\theta=T\left(\frac{p_{0}}{p}\right)^{0.286}$

where $T$ is the mean air temperature, $p$ is the ambient air pressure, and $p_{0}$ is $101 \mathrm{kPa}$.

In Eqs. (1) and (2), $\psi_{m}\left(\frac{z-d}{L}\right)$ and $\psi_{h}\left(\frac{z-d}{L}\right)$ are the stability correction factors for momentum and sensible heat 
transfers and they are determined according to atmospheric stratification (Panofsky 1963; Paulson 1970).

Equations (1) and (2) can be rearranged as

$$
\begin{aligned}
& u=\frac{u *}{k}\left[\ln (z-d)-\psi_{m}\left(\frac{z-d}{L}\right)\right]-\frac{u *}{k} \ln z_{o m} \\
& \theta=\frac{\theta *}{k}\left[\ln (z-d)-\psi_{h}\left(\frac{z-d}{L}\right)\right]-\left(\frac{\theta *}{k} \ln z_{o h}-\theta_{0}\right)
\end{aligned}
$$

Equations (5) and (6) can be expressed using a linear regression formula:

$$
y=a x+b
$$

For Eq. (5), $y=u, x=\ln (z-d)-\psi_{m}\left(\frac{z-d}{L}\right), a=u * / k$, and $b=-a \ln z_{o m}$. For Eq. (6), $y=\theta, x=\ln (z-d)-\psi_{h}\left(\frac{z-d}{L}\right)$, $a=\theta * / k$, and $b=-a \ln z_{o h}+\theta_{0}$.

If $d$ and $L$ are known, $z_{o m}, u *, z_{o h}$, and $\theta *$ can be determined by fitting the temperature and wind speed measured at different levels into Eq. (7). However, $u *$ and $\theta *$ are required to calculate $L$. Therefore, $z_{o m}, u *, z_{o h}$, and $\theta *$ are iteratively determined for a given $d$ value as follows.

(i) For given initial values of $u^{*}$ and $\theta^{*}, L$ is calculated using Eq. (3);

(ii) $z_{o m}, u *, z_{o h}$, and $\theta *$ are determined using Eq. (7);

(iii) $L$ is calculated with Eq. (3) using the values of $u *$ and $\theta *$ determined in step (ii).

Steps (ii) and (iii) are repeated until the difference in $L$ in two adjacent loops is less than 0.01 .

$u *$ could be directly measured using the eddy covariance system. In this study, $u *$ was determined employing the above iteration method. The eddy covariance system is not widely available, while the meteorological data required to determine $u *$ using the iteration method is easily acquired.

\subsubsection{Final Determination of $d$ and $z_{\text {om }}$}

The quantities $d$ and $z_{\text {om }}$ are interrelated. In this paper, $d$ and $z_{\text {om }}$ are concurrently optimized. Many experiments have shown that $d$ changes with vegetation and atmospheric stratification (Thom 1975; Pieke 1987). In this study, $d$ was determined through iteration. It was allowed to increase from 0.6 to $0.9 h$ ( $h$ is 12 and $26 \mathrm{~m}$ at QYZ and CBS, respectively) in intervals of $0.2 \mathrm{~m}$. For each given $d$, parameters $z_{o m}, u *$, $z_{o h}$, and $\theta *$ were determined using Eq. (7). The coefficients of correlation between measured and simulated wind speed and temperatures were simultaneously calculated. The optimum $d$ and $z_{o m}$ were finally determined when the coefficient of correlation between measured and simulated temperature reached a maximum.

\section{RESULTS AND DISCUSSIONS}

\subsection{Seasonal Variations in $z_{o m}$}

Figure 2 shows 5-day mean values and standard deviations of derived half-hourly $z_{\text {om }}$ in 2003 and 2004 at CBS and QYZ. At CBS, $z_{\text {om }}$ has obvious seasonal patterns over two years and is lower in the leaf-off season than in the growing season. The averages of half-hourly $z_{\text {om }}$ are 0.077 and 0.069 $h$ in growing and leaf-off seasons in 2003 and 0.091 and $0.072 h$ in 2004, respectively (Table 1). There is no obvious seasonal pattern of $z_{o m}$ at QYZ. However, $z_{o m}$ has larger short-term fluctuations at QYZ than at CBS. The coefficients of variation $(\mathrm{CV}=$ standard deviation/mean value $\times 100 \%)$ are $33.5 \%$ and $24.2 \%$ in 2003 and 2004 at QYZ and $18.8 \%$ and $17.1 \%$ at CBS respectively. The annual means of halfhourly $z_{\text {om }}$ are 0.083 and $0.097 h$ in 2003 and 2004 at QYZ and 0.072 and $0.079 h$ at CBS respectively. $z_{o m} / h$ is higher at QYZ than at CBS. It should be kept in mind that the canopy height at CBS is about twice that at QYZ. Whether and how $z_{\text {om }} / h$ decreases with $h$ requires further investigation.

At CBS, one of the major drivers of large seasonal variations in $z_{\text {om }}$ is the distinct seasonal pattern of the LAI, which increases from a minimum at the beginning of the growing season (early May) to a maximum in late June and starts to decrease in the middle of September (Zhou et al. 2006). The seasonal pattern of the 5-day mean of $z_{o m}$ closely follows that of the LAI. At the beginning of the growing season, the LAI is relatively low and new leaves are very soft. The resistance to flow on the canopy surface is small, which results in small $z_{o m}$. With increases in the LAI and aging of the leaves, the geometric roughness length and resistance increase. Consequently, $z_{o m}$ increases to a maximum. With the decrease in the LAI, $z_{\text {om }}$ starts to decrease in the middle of September. During the non-growing season, low canopy density results in low $z_{o m}$. The relationship between $z_{o m}$ and the LAI identified in this study is consistent with the findings reported by Shaw and Pereira (1982) and Raupach (1994), and in good agreement with the study posted by McDonald et al. (1998) and Shao and Yang (2008). McDonald et al. (1998) proposed a relationship between $z_{o m}$ and the ratio of the frontal area (or the plan area) of the obstacles to the lot area. It was shown that with the increase of the ratio, the $z_{o m} / h$ increase firstly, and then decrease. Shao and Yang (2008) also studied the theory for drag partition over rough surfaces, in which it was shown the same phenomenon with McDonald's results. Nevertheless, the phenomenon disagrees with Lindroth's (1993) study. Therefore, the relationship between $z_{\text {om }}$ and the LAI needs further study. For forests, $z_{o m} / h$ is a function not only of the LAI, but also of a density parameter, such as the frontal area index (Schaudt and Dickinson 2000) or stand density (Nakai et al. 2008a). However, data on the frontal area index and stand density were not easy to obtain thus far. Since the frontal area index and stand density are correlated with the LAI and the LAI 


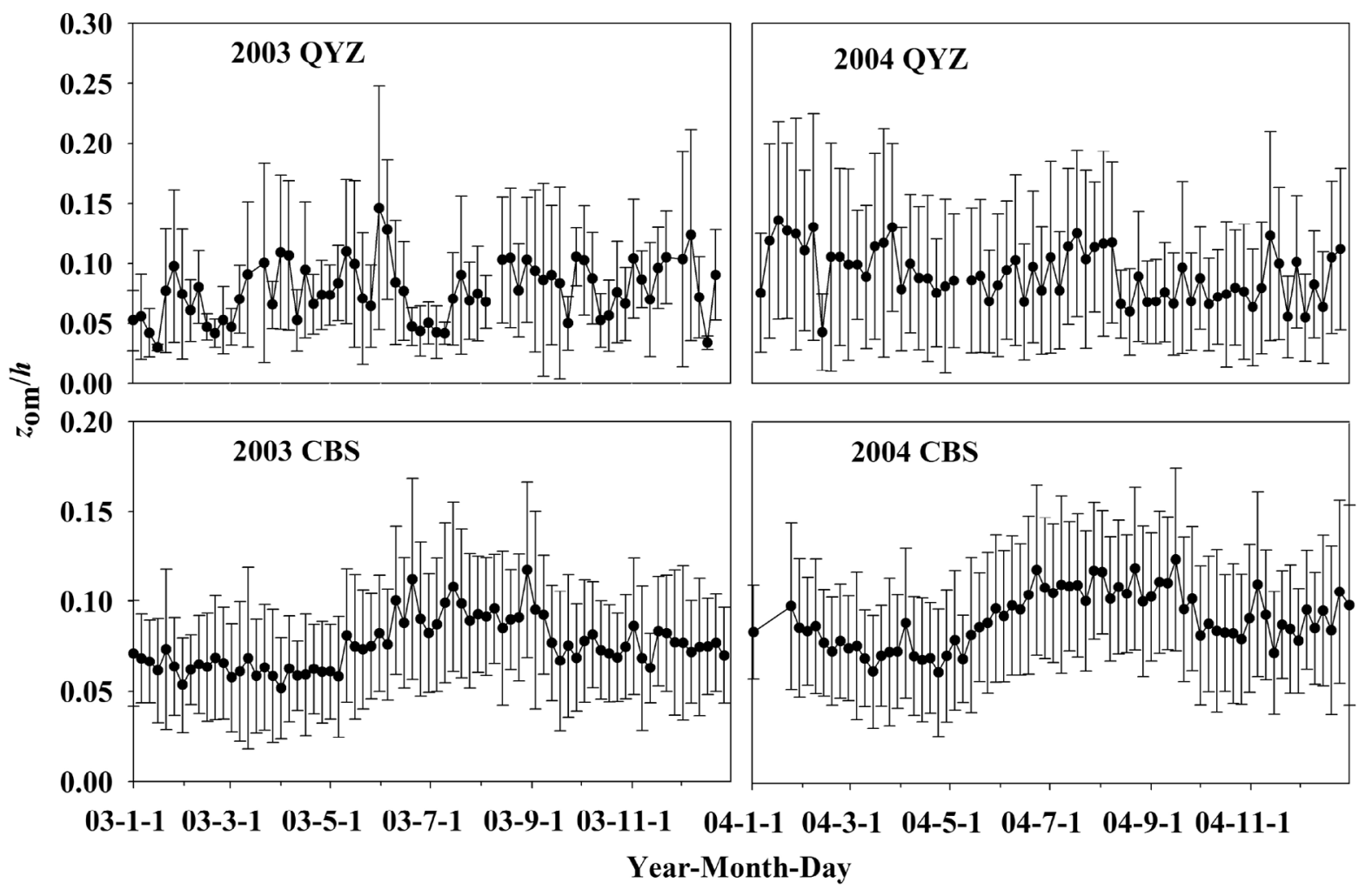

Fig. 2. Seasonal variations in $z_{o m}$ at QYZ and CBS in 2003 and 2004. Solid block points represent 5-day means of half-hourly $z_{o m}$. Error bars are the standard deviations of half-hourly $z_{o m}$.

Table 1. The annual averages and variation coefficients of half-hourly $z_{\text {om }}$ at CBS and QYZ in 2003 and 2004 and those values in the growing and non-growing seasons at CBS.

\begin{tabular}{cccccc}
\hline Site & Year & Annual average $z_{\text {om }}$ & $\begin{array}{c}\text { Average } z_{o m} \text { in the } \\
\text { growing seasons }\end{array}$ & $\begin{array}{c}\text { Average } z_{o m} \text { in the } \\
\text { non-growing seasons }\end{array}$ & $\begin{array}{c}\text { Coefficient of } \\
\text { variation }(\%)\end{array}$ \\
\hline QYZ & 2003 & $0.083 h$ & - & - & 33.5 \\
& 2004 & $0.097 h$ & & & 24.2 \\
CBS & 2003 & $0.072 h$ & $0.077 h$ & $0.069 h$ & 18.8 \\
& 2004 & $0.079 h$ & $0.091 h$ & $0.072 h$ & 17.1 \\
\hline
\end{tabular}

was easy to obtain by remote sensing, establishing relationships between the LAI and the frontal area index and stand density is helpful for $z_{o m}$ research; further study with data from more ecosystem stations is required.

\subsection{Wind-Direction-Dependent Variation of $z_{o m}$ over Heterogeneous Terrain}

It is well known that $z_{o m}$ calculated with wind speed profiles relates not only to the height of rough elements, but also to the distribution, density and geometry of rough elements (Taylor et al. 1989; Zhang et al. 2004; Zhou et al. 2005, 2009). $z_{o m}$ has more distinguishable short-term fluctuations at QYZ than at CBS, which is attributable to the different topographic characteristics of the two stations. The terrain is more heterogeneous at QYZ than at CBS. Additionally, the scopes of the regions were calculated with a flux source area model (FSAM) (Schmid et al. 1991; Schmid 1997, 2002) at QYZ and CBS. The FSAM footprint model is shown in Fig. 3, and the footprint results calculated with annually averaged $z_{o m}$ for the year 2003 are presented in Table 2. The scope length is about $1-2 \mathrm{~km}$ at both stations. At this scope, the $90 \mathrm{~m} \times 90 \mathrm{~m}$ digital elevation model (DEM) map shows that the topography is more heterogeneous at QYZ than at CBS (Fig. 1 and Table 3). Table 3 presents the means, standard deviation (STDEV), and CV of elevations within $2 \mathrm{~km}$ $\times 2 \mathrm{~km}$ and $4 \mathrm{~km} \times 4 \mathrm{~km}$ squares centered on the towers. The CVs of elevations are $14 \%$ and $22 \%$ for the $2 \mathrm{~km} \times 2 \mathrm{~km}$ and 
$4 \mathrm{~km} \times 4 \mathrm{~km}$ squares at QYZ, respectively, but only $3 \%$ and $4 \%$ at CBS (Table 3 ).

The heterogeneous topography causes $z_{\text {om }}$ to change with wind direction at QYZ (Fig. 4). The average of $z_{o m}$ at QYZ decreases by more than $50 \%$ when the wind is from the north and northwest and south and southwest relative to the average of $z_{\text {om }}$ for wind in other directions. With the wind direction change, $z_{o m}$ has distinguishable short-term fluctuations. The change in $z_{o m}$ with wind direction is less obvious at CBS than at QYZ. Consequently, the short-term fluctuation of $z_{o m}$ at CBS is relatively small.

Topographic characteristics are thus the main factors explaining the difference in short-term fluctuations of $z_{\text {om }}$ at QYZ and CBS. In heterogeneous regions with undulant terrain, rough elements and their distribution change with wind directions. This leads to large wind-direction-dependent variations and short-term fluctuations of $z_{o m}$ in heterogeneous terrain.

\subsection{Diurnal Variations of $z_{o m}$}

Annually and monthly averaged diurnal variations of half-hourly $z_{o m}$ in 2003 and 2004 were calculated. Figure 5 shows the annually averaged diurnal variations of half-hourly $z_{o m}$ in 2003 and 2004. The annual mean diurnal variations of $z_{o m}$ are almost identical for the two years. $z_{o m}$ is much

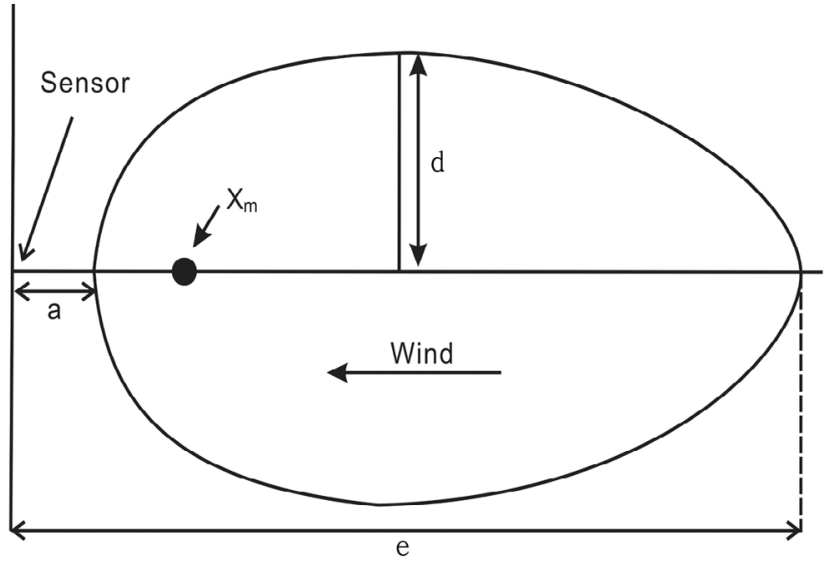

Fig. 3. Characteristic dimensions of the source area. $x_{m}$ : location of maximum source; $a$ : near end; $e$ : far end; and $d$ : maximum lateral halfwidth of the source area [source from Schmid et al. (1991)].

Table 2. Outputs of FSAM at QYZ and CBS.

\begin{tabular}{cccc}
\hline Station & $\boldsymbol{a}(\mathbf{m})$ & $\boldsymbol{e}(\mathbf{m})$ & $\boldsymbol{d}(\mathbf{m})$ \\
\hline QYZ & 270.1 & 2620.2 & 712.8 \\
CBS & 147.4 & 1810.9 & 293.8 \\
\hline
\end{tabular}

Note: The meanings of $a, d$, e are according to Fig. 3. a: near end; $d$ : maximum lateral half-width of the source area; and e: far end.

Table 3. The mean value (MEAN), standard deviation (STDEV) and coefficient of variation (CV) of elevations within $2 \mathrm{~km} \times 2 \mathrm{~km}$ and $4 \mathrm{~km} \times 4 \mathrm{~km}$ squares surrounding the towers at QYZ and CBS.

\begin{tabular}{ccccc}
\hline SITE & QYZ $(\mathbf{2} \mathbf{~ k m} \times \mathbf{2} \mathbf{~ k m})$ & $\mathbf{C B S}(\mathbf{2} \mathbf{~ k m} \times \mathbf{2} \mathbf{~ k m})$ & $\mathbf{Q Y Z}(\mathbf{4} \mathbf{~ k m} \times \mathbf{4} \mathbf{~ k m})$ & $\mathbf{C B S}(\mathbf{4} \mathbf{~ k m} \times \mathbf{4} \mathbf{~ k m})$ \\
\hline MEAN (m) & 118.94 & 750.43 & 107.48 & 750.97 \\
$\operatorname{STDEV}(\mathrm{m})$ & 16.76 & 20.51 & 23.97 & 27.72 \\
$\mathrm{CV}(\%)$ & 14 & 3 & 22 & 4 \\
\hline
\end{tabular}
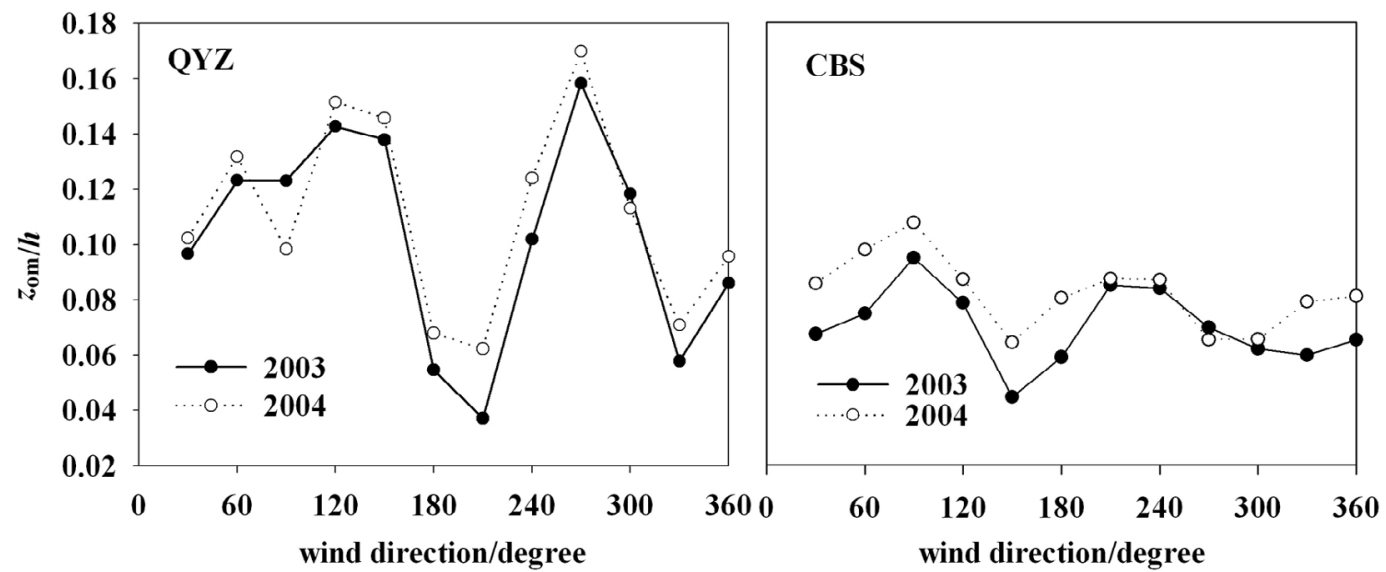

Fig. 4. Changes in averaged half-hourly $z_{\text {om }}$ with wind direction at QYZ and CBS in 2003 and 2004. $z_{\text {om }}$ values are binned in wind-direction intervals of $30^{\circ}$. 


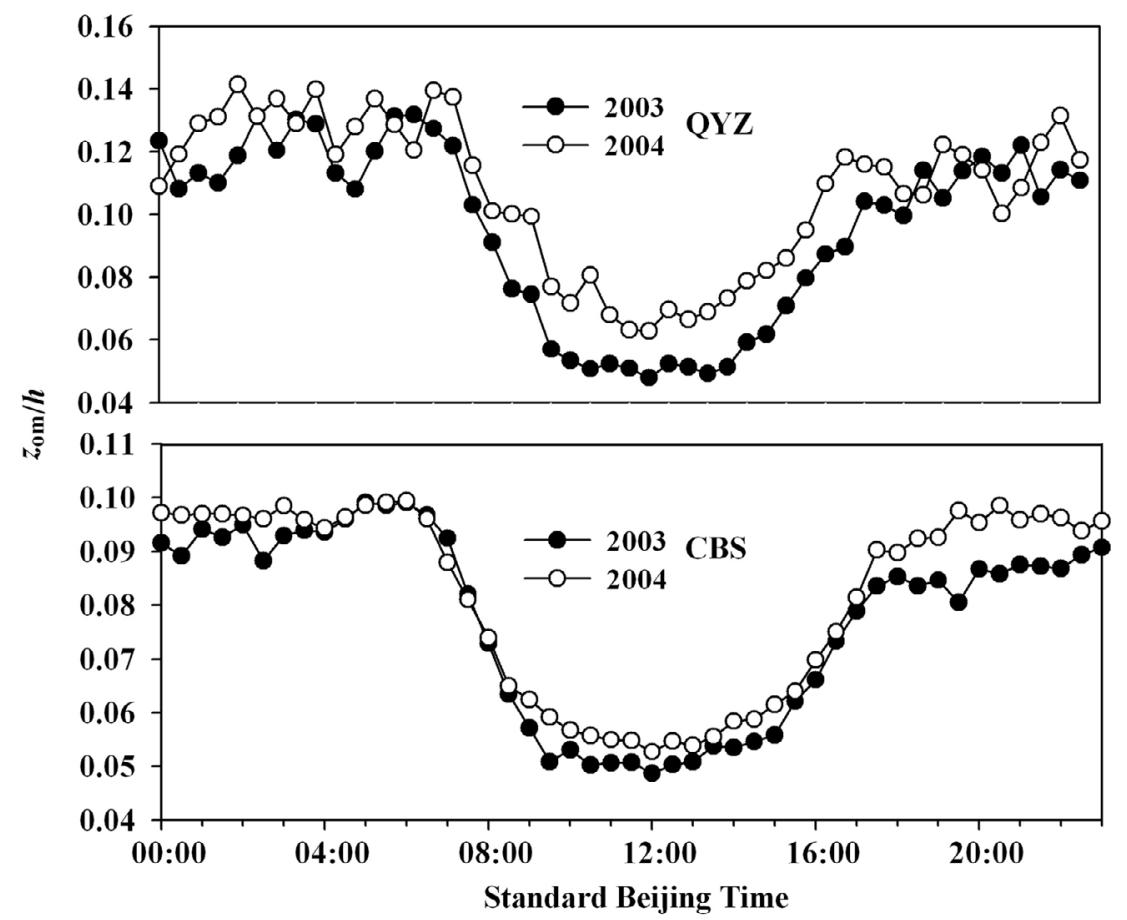

Fig. 5. Annually averaged diurnal variations of $z_{\text {om }}$ at QYZ and CBS in 2003 and 2004.

larger at night (18:00 to 8:00) than during the day (8:00 to 18:00). It gradually decreases after sunrise and approaches a minimum at noon. It then increases until sunset. The slight increase in $z_{\text {om }}$ continues during the period from sunset to midnight. The variation range of $z_{o m}$ is larger during the day than during the night. At QYZ, the annual means of daytime $z_{o m}$ are 0.065 and $0.084 h$ while those of nighttime $z_{\text {om }}$ are 0.115 and $0.124 h$ in 2003 and 2004, respectively. At CBS, the daytime averages of $z_{o m}$ are 0.06 and $0.064 h$ and the nighttime averages of $z_{o m}$ are 0.091 and $0.094 h$ in 2003 and 2004 , respectively (Table 4). The obvious diurnal variation in $z_{o m}$ is usually neglected in most models. This simplification would inevitably result in the failure of models to capture the diurnal patterns of fluxes.

The diurnal variations in $z_{\text {om }}$ are related to diurnal changes in atmospheric stratifications (Liu et al. 1989; Chen et al. 1993; Lv and Dong 2004; Mao et al. 2006). During the day, atmospheric stratification is unstable and the Richardson number $\left(R_{i}\right)$, which is an indicator of atmospheric stratification, is negative. The turbulence between vegetation canopy and the atmosphere is so intensive that it is easy for momentum to transfer between vegetation and the atmosphere. Consequently, $z_{\text {om }}$ is lower. At night or in early morning, the atmospheric stratification is stable or neutral and $R_{i}$ is no less than zero. The turbulence between vegetation and the atmosphere is so weak that it is difficult for the momentum to transfer between vegetation and the atmosphere. $z_{o m}$ is consequently high (Liu et al. 1989; Chen et al. 1993; Mao et al. 2006). In all wind directions, the aver- age of $z_{o m}$ is highest under stable atmospheric stratification and lowest under unstable atmospheric stratification. The variation in $z_{o m}$ with atmospheric stratification over the Gobi and vegetation surfaces was previously reported by Lv and Dong (2004).

Monthly averaged diurnal variations of half-hourly $z_{o m}$ in 2003 and 2004 at QYZ and CBS are shown in Fig. 6. At both QYZ and CBS, $z_{\text {om }}$ has diurnal variations and is much higher at night (18:00 to 8:00) than during the day (8:00 to 18:00) in all months from January to December, which is consistent with the nature of the annually averaged diurnal variations. $z_{o m}$ is much higher during times of full foliage than in barren periods at CBS, which is also consistent with the seasonal variations of $z_{o m}$. Furthermore, at CBS in the leaf-off season, the difference between $z_{\text {om }}$ during the day and at night is about $0.06 h$, and during times of full foliage, the difference reaches $0.08 \mathrm{~h}$. Meanwhile, at QYZ, monthly averaged diurnal variations in $z_{o m}$ have no seasonal variations, and $z_{o m}$ during the day and at night is about $0.09 h$, which is higher than that at CBS. Additionally, the monthly averaged $z_{\text {om }}$ at QYZ has obvious short-term fluctuations.

\section{CONCLUSIONS}

In this study, $z_{o m}$ was derived from the wind speed and temperatures measured at four heights in two typical forest ecosystems (CBS and QYZ) in China, and the temporal characteristics of $z_{o m}$ at the two sites were analyzed. From this study, the following conclusions can be drawn. 
Table 4. Annual averages of half-hourly $z_{\text {om }}$ during daytime and at night at CBS and QYZ in 2003 and 2004.

\begin{tabular}{cccc}
\hline Station & Year & $\begin{array}{c}\text { Annual mean of } z_{\text {om }} \text { during } \\
\text { daytime (8:00 to 18:00) }\end{array}$ & $\begin{array}{c}\text { Annual mean of } z_{\text {om }} \text { during } \\
\text { night time (18:00 to 8:00 ) }\end{array}$ \\
\hline QYZ & 2003 & $0.065 h$ & $0.115 h$ \\
& 2004 & $0.084 h$ & $0.124 h$ \\
\multirow{2}{*}{ CBS } & 2003 & $0.06 h$ & $0.091 h$ \\
& 2004 & $0.064 h$ & $0.094 h$ \\
\hline
\end{tabular}
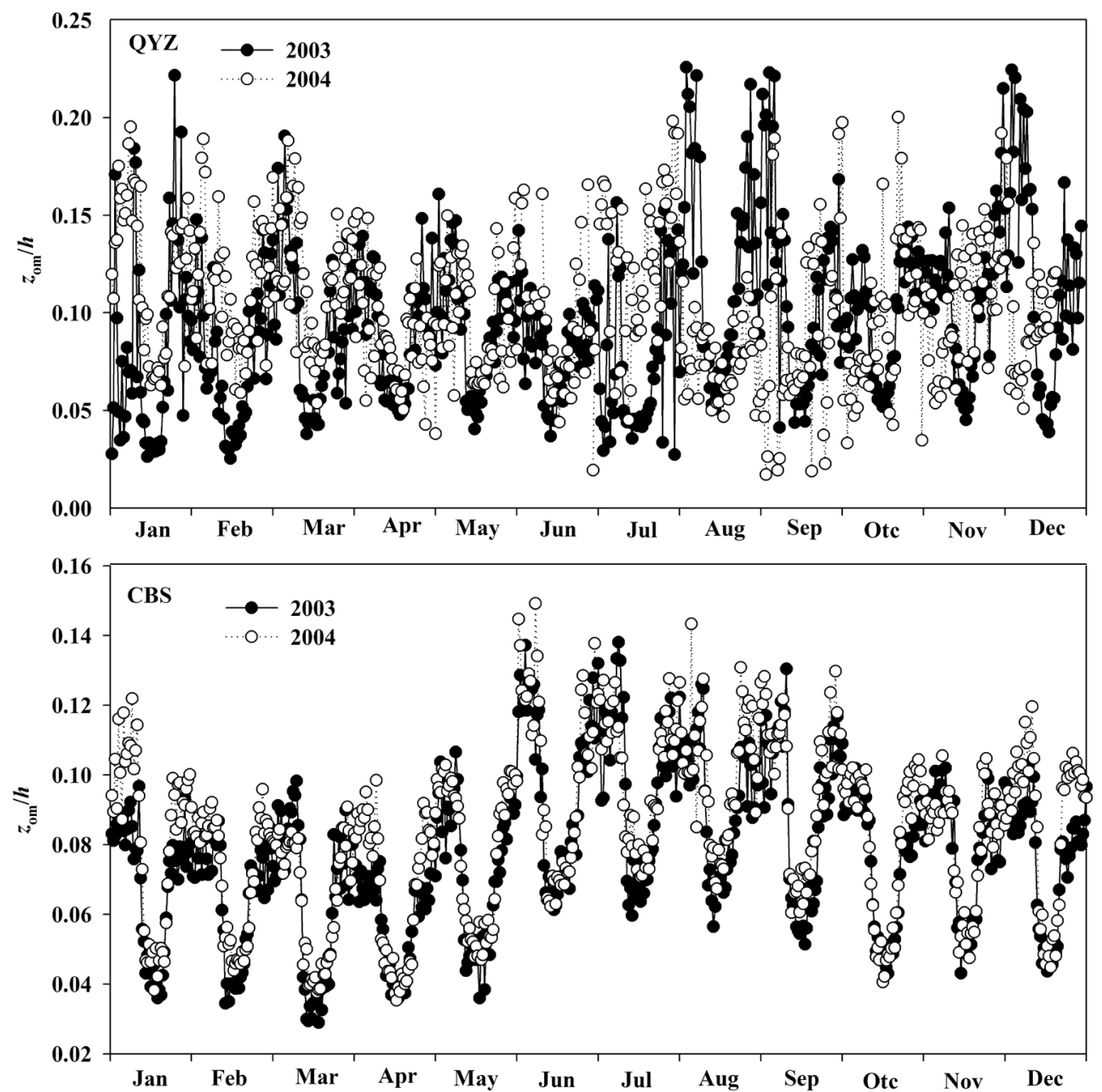

Fig. 6. Monthly averaged diurnal variations of $z_{\text {om }}$ at QYZ and CBS in 2003 and 2004.

$z_{o m}$ has obvious seasonal variations at CBS, in that it is much higher in the growing season than in the leaf-off period. It does not have obvious seasonal variation at QYZ. The noticeable seasonal variation of $z_{o m}$ is mostly related to the large seasonal change in the LAI at CBS. The short-term fluctuation of $z_{o m}$ is more obvious at QYZ than at CBS since the terrain at QYZ is more heterogeneous.

At QYZ and CBS, $z_{\text {om }}$ has similarly obvious diurnal variations. It is much lower during the day than at night owing to the difference in atmospheric stratification during these two periods. $z_{o m}$ is lower for unstable atmospheric stratification (mostly during the day) than for neutral or stable atmospheric stratification (mostly at night or in the early morning).

At QYZ, $z_{o m}$ having noticeable short-term fluctuation is attributable to the heterogeneous terrain in this region, which reflects the wind-direction-dependent variation in $z_{o m}$ where there is heterogeneous terrain. 
Acknowledgements This research was funded by the National Natural Science Foundation of China (Grant Nos. 40901033/D010104 and 40871240/D011004), National Key Basic Research Project of China (Grant No. 2010CB833501) and a project funded by the Priority Academic Program Development of Jiangsu Higher Education Institutions. We thank the Data Sharing Infrastructure of Earth System Science for providing DEM data of the Qianyanzhou and Changbai Mountain Experimental Stations. We gratefully acknowledge the reviewers for their constructive comments.

\section{REFERENCES}

Baldocchi, D., 1994: A comparative study of mass and energy exchange rates over a closed $\mathrm{C}_{3}$ (wheat) and an open $\mathrm{C}_{4}$ (corn) crop: II. $\mathrm{CO}_{2}$ exchange and water use efficiency. Agric. For. Meteorol., 67, 291-321, doi: 10.10 16/0168-1923(94)90008-6. [Link]

Berkowicz, R. and L. P. Prahm, 1982: Evaluation of the profile method for estimation of surface fluxes of momentum and heat. Atmos. Environ., 16, 2809-2819.

Borak, J. S., M. F. Jasinski, and R. D. Crago, 2005: Time series vegetation aerodynamic roughness fields estimated from MODIS observations. Agric. For. Meteorol., 135, 252-268, doi: 10.1016/j.agrformet.2005.12.006. [Link]

Chen, J. Y., J. M. Wang, and M. Yasushi, 1993: An independent method to determine the surface roughness length. Chin. J. Atmos. Sci., 17, 21-26. (in Chinese)

Dolman, A. J., 1986: Estimates of roughness length and zero plane displacement for a foliated and non-foliated oak canopy. Agric. For. Meteorol., 36, 241-248, doi: 10.1016/0168-1923(86)90038-9. [Link]

Driese, K. L. and W. A. Reiners, 1997: Aerodynamic roughness parameters for semi-arid natural shrub communities of Wyoming, USA. Agric. For. Meteorol., 88, 1-14, doi: 10.1016/S0168-1923(97)00055-5. [Link]

Falge, E., D. Baldocchi, R. Olson, P. Anthoni, M. Aubinet, C. Bernhofer, G. Burba, R. Ceulemans, R. Clement, H. Dolman, A. Granier, P. Gross, T. Grunwald, D. Hollinger, N.-O. Jensen, G. Katul, P. Keronen, A. Kowalski, C. T. Lai, B. E. Law, T. Meyers, J. Moncrieff, E. Moors, J. W. Munger, K. Pilegaard, U. Rannik, C. Rebmann, A. Suyker, J. Tenhunen, K. Tu, S. Verma, T. Vesala, K. Wilson, and S. Wofsy, 2001: Gap filling strategies for defensible annual sums of net ecosystem exchange. Agric. For. Meteorol., 107, 43-69, doi: 10.1016/S0168-1923(00)00225-2. [Link]

Gao, Z. Q., L. G. Bian, C. G. Lu, L. H. Lu, J. X. Wang, and Y. Wang, 2002: Estimation of aerodynamic parameters in urban areas. J. Appl. Meteorol. Sci., 13, 26-33. (in Chinese)

Guan, D., J. Wu, G. Yu, X. Sun, X. Zhao, S. Han, and C. Jin, 2005: Meteorological control on $\mathrm{CO}_{2}$ flux above broad-leaved Korean pine mixed forest in Changbai Mountains. Sci. Chin. Ser. D: Earth Sci., 48 (Supp. 1), 116-122.

Hurtalová, T. and F. Matejka, 1999: Surface characteristics and energy fluxes above different plant canopies. Agric. For. Meteorol., 98-99, 491-499, doi: 10.1016/ S0168-1923(99)00118-5. [Link]

Kustas, W. P., B. J. Choudhury, M. S. Moran, R. J. Reginato, R. D. Jackson, L. W. Gay, and H. L. Weaver, 1989: Determination of sensible heat flux over sparse canopy using thermal infrared data. Agric. For. Meteorol., 44, 197-216, doi: 10.1016/0168-1923(89)900178. [Link]

Langensiepen, M., M. Fuchs, H. Bergamaschi, S. Moreshet, Y. Cohen, P. Wolff, S. C. Jutzi, S. Cohen, L. M. G. Rosa, Y. Li, and T. Fricke, 2009: Quantifying the uncertainties of transpiration calculations with the Penman-Monteith equation under different climate and optimum water supply conditions. Agric. For. Meteorol., 149, 1063-1072, doi: 10.1016/j.agrformet.2009.01.001. [Link]

Li, C., H. L. He, M. Liu, W. Su, Y. L. Fu, L. M. Zhang, X. F. Wen, and G. R. Yu, 2008: The design and application of $\mathrm{CO} 2$ flux data processing system at ChinaFLUX. Geo-Inform. Sci., 10, 557-565. (in Chinese)

Lindroth, A., 1993: Aerodynamic and canopy resistance of short-rotation forest in relation to leaf area index and climate. Bound.-Layer Meteor., 66, 265-279, doi: 10.1007/BF00705478. [Link]

Liu, S. H., 1989: The definition of aerodynamic parameters in the wheat fields and their analysis. Meteorology, 15, 8-13. (in Chinese)

Liu, Y., X. Song, G. Yu, X. Sun, X. Wen, and Y. Chen, 2005: Seasonal variation of $\mathrm{CO}_{2}$ flux and its environmental factors in evergreen coniferous plantation. Sci. Chin. Ser. D: Earth Sci., 48 (Supp. 1), 123-132.

Liu, Y., G. Yu, X. Wen, Y. Wang, X. Song, J. Li, X. Sun, F. Yang, Y. Chen, and Q. Liu, 2006: Seasonal dynamics of $\mathrm{CO}_{2}$ fluxes from subtropical plantation coniferous ecosystem. Sci. Chin. Ser. D: Earth Sci., 49 (Supp. 2), 99-109, doi: 10.1007/s11430-006-8099-3. [Link]

Lv, P. and Z. B. Dong, 2004: Determination of roughness length on gobi deflation plane and vegetation surface. J. Desert Res., 24, 279-285. (in Chinese)

Mao, Y., S. Liu, and J. Li, 2006: Study of aerodynamic parameters for different underling surfaces. Acta Meteorol. Sin., 64, 325-334. (in Chinese)

Martano, P., 2000: Estimation of surface roughness length and displacement height from single-level sonic anemometer data. J. Appl. Meteorol., 39, 708-715, doi: 10.1175/1520-0450(2000)039<0708:EOSRLA>2.0.C O;2. [Link]

Monteith, J. L., 1973: Principles of Environmental Physics, London, Edward Arnold. 
Nakai, T., A. Sumida, K. Daikoku, K. Matsumoto, M. K. Molen, Y. Kodama, A. V. Kononov, T. C. Maximov, A. J. Dolman, H. Yabuki, T. Hara, and T. Ohta, 2008a: Parameterisation of aerodynamic roughness over boreal, cool- and warm-temperate forests. Agric. For. Meteorol., 148, 1916-1925, doi: 10.1016/j.agrformet.2008. 03.009. [Link]

Nakai, T., A. Sumida, K. Matsumoto, K. Daikoku, S. Iida, H. Park, M. Miyahara, Y. Kodama, A. V. Kononov, T. C. Maximov, H. Yabuki, T. Hara, and T. Ohta, 2008b: Aerodynamic scaling for estimating the mean height of dense canopies. Bound.-Layer Meteor., 128, 423-443, doi: 10.1007/s10546-008-9299-5. [Link]

Nakai, T., A. Sumida, Y. Kodama, T. Hara, and T. Ohta, 2010: A comparison between various definitions of forest stand height and aerodynamic canopy height. Agric. For. Meteorol., 150, 1225-1233, doi: 10.1016/j. agrformet.2010.05.005. [Link]

Panofsky, H. A., 1963: Determination of stress from wind and temperature measurements. Q. J.R. Meteorol. Soc., 89, 85-94, doi: 10.1002/qj.49708937906. [Link]

Patil, M. N, 2006: Aerodynamic drag coefficient and roughness length for three seasons over a tropical western Indian station. Atmos. Res., 80, 280-293, doi: 10.1016/j. atmosres.2005.10.005. [Link]

Paulson, C. A., 1970: The mathematical representation of wind speed and temperature profiles in the unstable atmospheric surface layer. J. Appl. Meteorol., 9, 857861, doi: 10.1175/1520-0450(1970)009<0857:TMRO WS $>2.0 . C O ; 2$. [Link]

Pieke, R. A., 1987: Mesoscale meteorological modeling, Beijing, China Meteorological Press. (in Chinese)

Pitman, A. J., 1994: Assessing the sensitivity of a land-surface scheme to the parameter values using a single column model. J. Climate, 7, 1856-1869, doi: 10.1175/15 20-0442(1994)007<1856:ATSOAL>2.0.CO;2. [Link]

Raupach, M. R., 1994: Simplified expressions for vegetation roughness length and zero-plane displacement as functions of canopy height and area index. Bound.Layer Meteor., 71, 211-216, doi: 10.1007/BF00709229. [Link]

Riou, C., P. Pieri, and C. Valancogne, 1987: Variation de la vitesse du vent a l'intérieur et au-dessus d'une vigne. Agric. For. Meteorol., 39, 143-154, doi: 10.1016/016 8-1923(87)90033-5. [Link]

Sánchez, J. M., V. Caselles, R. Niclós, C. Coll, and W. P. Kustas, 2009: Estimating energy balance fluxes above a boreal forest from radiometric temperature observations. Agric. For. Meteorol., 149, 1037-1049, doi: 10. 1016/j.agrformet.2008.12.009. [Link]

Schaudt, K. J. and R. E. Dickinson, 2000: An approach to deriving roughness length and zero-plane displacement height from satellite data, prototyped with BOREAS data.Agric.For.Meteorol., 104,143-155, doi: 10.1016/
S0168-1923(00)00153-2. [Link]

Schmid, H. P., 1997: Experimental design for flux measurements: Matching scales of observations and fluxes. $\mathrm{Ag}$ ric. For. Meteorol., 87, 179-200, doi: 10.1016/S01681923(97)00011-7. [Link]

Schmid, H. P., 2002: Footprint modeling for vegetation atmosphere exchange studies: A review and perspective. Agric. For. Meteorol., 113, 159-183, doi: 10.1016/S01 68-1923(02)00107-7. [Link]

Schmid, H. P., H. A. Cleugh, C. S. B. Grimmond, and T. R. Oke, 1991: Spatial variability of energy fluxes in suburban terrain. Bound.-Layer Meteor., 54, 249-276, doi: 10.1007/BF00183956. [Link]

Shao, Y. and Y. Yang, 2008: A theory for drag partition over rough surfaces. J. Geophys. Res., 113, F02S05, doi: 10.1029/2007JF000791. [Link]

Shaw, R. H. and A. R. Pereira, 1982: Aerodynamic roughness of a plane canopy: A numerical experiment. $\mathrm{Ag}$ ric. For. Meteorol., 26, 51-65.

Soegaard, H. and H. Thorgeirsson, 1998: Carbon dioxide exchange at leaf and canopy scale for agricultural crops in the boreal environment. J. Hydrol., 212-213, 51-61, doi: 10.1016/S0022-1694(98)00201-7. [Link]

Su, Z., 2002: The Surface Energy Balance System (SEBS) for estimation of turbulent heat fluxes. Hydrol. Earth Syst. Sci.. 6, 85-100, doi: 10.5194/hess-6-85-2002. [Link]

Su, Z., T. Schmugge, W. P. Kustas, and W. J. Massman, 2001: An evaluation of two models for estimation of the roughness height for heat transfer between the land surface and the atmosphere. J. Appl. Meteorol., 40, 1933-1951, doi: 10.1175/1520-0450(2001)040<1933: AEOTMF>2.0.CO;2. [Link]

Takagi, K., A. Miyata, Y. Harazono, N. Ota, M. Komine, and M. Yoshimoto, 2003: An alternative approach to determining zero-plane displacement, and its application to a lotus paddy field. Agric. For. Meteorol., 115, 173181, doi: 10.1016/S0168-1923(02)00209-5. [Link]

Taylor, P. A., R. I. Sykes, and P. J. Mason, 1989: On the parameterization of drag over small-scale topography in neutrally-stratified boundary-layer flow. Bound.Layer Meteor., 48, 409-422, doi: 10.1007/BF00123062. [Link]

Teixeira, A. H. de C., W. G. M. Bastiaanssen, M. D. Ahmad, M. S. B. Moura, and M. G. Bos, 2008: Analysis of energy fluxes and vegetation-atmosphere parameters in irrigated and natural ecosystems of semi-arid Brazil. J. Hydrol., 362, 110-127, doi: 10.1016/j.jhydrol. 2008.08.011. [Link]

Thom, A. S., J. B. Stewart, H. R. Oliver, and J. H. C. Gash, 1975: Comparison of aerodynamic and energy budget estimates of fluxes over a pine forest. Q. J. R. Meteorol. Soc., 101, 93-105, doi: 10.1002/qj.49710142708. [Link] 
Van Dijk, A. I. J. M., L. A. S. Bruijnzeel, and J. Schellekens, 2004: Micrometeorology and water use of mixed crops in upland West Java, Indonesia. Agric. For. Meteorol., 124, 31-49, doi: 10.1016/j.agrformet.2004. 01.006. [Link]

Zhang, H. and J. Chen, 1997: Estimation of aerodynamic parameters on non-single horizontal homogeneous underlying surface. Q. J. Appl. Meteorol., 8, 310-315. (in Chinese)

Zhang, J., G. Yu, S. Han, D. Guan, and X. Sun, 2006: Seasonal and annual variation of $\mathrm{CO}_{2}$ flux above a broadleaved Korean pine mixed forest. Sci. Chin. Ser. D: Earth Sci., 49 (Supp. 2), 63-73, doi: 10.1007/s11430006-8063-2. [Link]

Zhang, R., J. Wang, C. Zhu, X. Sun, and Z. Zhu, 2004: The retrieval of two-dimensional distribution of the earth's surface aerodynamic roughness using SAR image and
TM thermal infrared image. Sci. Chin. Ser. D: Earth Sci., 47, 1134-1146.

Zhou Y., X. Sun, R. Zhang, Z. Zhu, J. Tian, J. Xu, and Z. $\mathrm{Li}, 2005$ : the improvement and validation of the model for retrieving the effective roughness length on TM pixel scale. IEEE 2005 International Geoscience and Remote Sensing Symposium, Korea.

Zhou, Y., X. Sun, Z. Zhu, R. Zhang, J. Tian, Y. Liu, D. Guan, and G. Yuan, 2006: Surface roughness length dynamic over several different surfaces and its effects on modeling fluxes. Sci. Chin. Ser. D: Earth Sci., 49 (Supp. 2), 262-272, doi: 10.1007/s11430-006-8262-x. [Link]

Zhou, Y., X. Sun, Z. Zhu, X. Wen, J. Tian, and R. Zhang, 2007: Comparative research on four typical surface roughness length calculation methods. Geogr. Res., 26, 887-896. (in Chinese) 